\title{
Semen analysis and sperm function parameters in patients with infertility in Navi Mumbai and Panvel region
}

\author{
Surekha Bhalekar ${ }^{1}$, Shweta Ganorkar ${ }^{1 *}$, Hemant Bhalekar², Prakash Roplekar $^{1}$
}

\author{
${ }^{1}$ Department of Pathology, D. Y. Patil University School of Medicine, Navi Mumbai, Maharashtra, India \\ ${ }^{2}$ Department of Pathology, Dr. Bhalekar's Pathology Laboratory, Navi Mumbai, Maharashtra, India
}

Received: 13 September 2019

Accepted: 10 October 2019

\author{
*Correspondence: \\ Dr. Shweta Ganorkar, \\ E-mail: academicssdg@gmail.com
}

Copyright: () the author(s), publisher and licensee Medip Academy. This is an open-access article distributed under the terms of the Creative Commons Attribution Non-Commercial License, which permits unrestricted non-commercial use, distribution, and reproduction in any medium, provided the original work is properly cited.

\begin{abstract}
Background: Although semen analysis is routinely used to evaluate male partner in infertile couples, infertility and problems of impaired fecundity have been a concern through ages and is also a significant clinical problem today, which affects $8-12 \%$ of couples worldwide. Aim of the study was to study different semen parameters in male factor infertility (MFI) and thus increasing the awareness regarding same.

Methods: This is cross sectional study conducted between period of September 2016 to December 2018. Semen of 150 patients were studied and results were analysed as per recent WHO (2010) criteria.

Results: The present study included 150 patients whose age ranged from 24 to 51 years. Patients were divided into different age groups and sperm count was studied in each group. Abnormal sperm morphology was studied with respect to sperm head, neck, tail defects and combined defects. Sperm deformity index (SDI) and Teratozoospermic index (TZI) were calculated. Other parameters including semen volume, $\mathrm{pH}$, liquefaction time, sperm vitality and motility were also studied which showed significant variations.

Conclusions: Although semen analysis is first and most informative investigation for evaluation of male factor infertility, studying individual semen parameters and sperm function and increasing its awareness in general population especially in developing countries is equally important. Besides, it is necessary to acknowledge its limitation with respect to collection, processing, evaluation and biological variation of samples. Also, a normal semen analysis may not prove successful fertility potential of an individual.
\end{abstract}

Keywords: Male factor infertility, Morphological defects, Sperm count, Sperm indices

\section{INTRODUCTION}

The investigations of infertile couple mainly cater around female partner, however male partner needs to be screened alongside as male related factor is solely responsible in about $20 \%$ of cases of infertility and is a contributory factor in another $30 \%-40 \% .^{1}$ Alterations in normal physiology of reproductive organs affecting sperm functions ultimately results in oligozoospermia (low sperm count), teratozoospermia (abnormal morphology), azoospermia (sperm's absence in ejaculation) asthenozoospermia (loss of motility). This results in unsuccessful fertilization. Thus, pathogenesis is multifactorial. $^{2,3}$ Also when genderwise fertility or fecundity is looked upon, women are fertile for certain duration in their entire life thus offering a rate limiting step because of the regulated monthly production of ova and other barriers during and around pregnancy. Men on the other hand have no such barriers and are regular producers. This makes them fertile during their entire reproductive life if fecundity is to be tested. Hence, any abnormality in spermatogenesis can affect species renewal and propagation. 
Various studies have been published supporting a decline in sperm quality or dismissing the same. ${ }^{4-8}$ The decline in the semen quality coincides with an increasing incidence of abnormalities of the male genital tract including testicular cancer and cryptorchidism in various countries. ${ }^{9}$

Hence, semen analysis remains the single most useful and fundamental investigation with a sensitivity of $89.6 \% .{ }^{10} \mathrm{It}$ is a simple test that assesses the formation and maturity along with sperm interactions in seminal fluid. It also provides insight not only on sperm production (count), but the sperm quality (motility, morphology) as well. ${ }^{11}$

Societal pressure and dilemma surrounds the investigation of the male. A complete history and physical examination of the male partner is mandatory in cases of primary or secondary infertility. In most instances, the next step will be to order semen analysis as it is an easy non-invasive test which provides baseline information and a path to further investigations.

\section{The purpose of the study was to}

- Evaluate sperm characteristics in patients undergoing infertility evaluation.

- To help decide further modality of treatment.

\section{METHODS}

This is cross sectional study conducted between period of September 2016 to December 2018.

\section{Study population}

- Infertile couples in which the female partners had normal results on fertility evaluation were included. All of these couples had been unable to conceive for minimum of 12 months

- The women were required to have regular menstrual cycle, normal results on laparoscopy and hysterosalphingography and a luteal-phase endometrial biopsy specimen that was histologically consistent with menstrual dating

- All the men were required to be between the ages of 20 and 55 years at the time of enrollment.

\section{Semen collection and laboratory evaluation}

- Written informed consent was obtained from all participants after recruitment

- The study population comprised of 150 male patients referred to the laboratory for semen analysis for primary or secondary infertility. After providing proper instructions to the person regarding semen collection, samples were collected after a minimum of 48 hours but no longer than 7 days of sexual abstinence. Increased sperm concentration is associated with prolonged abstinence while improved motility is associated with shorter period of abstinence but with lower sperm density. The sperm morphology does not vary with length of sexual abstinence. ${ }^{10}$

- Semen samples were collected by masturbation at the laboratory. All semen analyses were performed manually within one hour after the sample was collected

- It included measurements of the volume, $\mathrm{pH}$, liquefaction time and presence of pus cells and viable sperms in the ejaculate (vitality test) and determinations of the sperm count, sperm concentration and the percentage of sperm with evidence of flagellar movement (percentage motility). Sperm deformity index (SDI) and teratozoospermic index (TZI) were also counted. Fructose content of sample was also estimated. Hypo-osmotic swelling test was also performed

- Sperm count was done on 10-microns depth chamber - sperm meter

(Product code SP/INT/001-A) of Sperm Processor company.

\section{0-microns depth chamber-sperm meter}

- Sperm Meter requires no dilution of semen, so only a 'neat semen' is analysed resulting in more accuracy. It is designed to achieve uniform smear of 10 micron thickness which allows free head movements of sperms in all directions. This also avoids overlapping of sperms

- It has a micrometric grid of 100 squares; each of 100 micron. The number of sperms in any 10 squares of the grid, simply implies their concentration in million per $\mathrm{ml}$

- The cases with nil sperms were re-evaluated on three occasions before labeling them as azoospermia. Sperm motility was assessed by direct visualization under the microscope

- Semen smears were fixed and stained at the laboratory by the Papanicolaou method for assessment of sperm morphology by light microscopy. Sperms were classified as having normal or abnormal morphologic features including defective morphology of head, neck or tail according to strict criteria.

\section{Ethical consideration}

- The study was conducted in accordance with the principles of Declaration of Helsinki (World Medical Association) and Good Clinical Practice guidelines issued by the ICMR. All the patient's confidentiality was maintained.

\section{Statistical analysis}

- All data was entered in Microsoft Excel (MS office version 2010) and tabulated. Data analysis was done using Windows PC based software "MedCalc 
Statistical Software" version 18.2.1 (MedCalc Software bvba, Ostend, Belgium; http://www.medcalc.org; 2018). Data for all analysis was done at alpha 0.05 (95\% confidence limits)

- Data expression

- The measurement data for the flow $(\mathrm{mm})$ is expressed as means with SD/SEM and median

- Kolmogorov-Smirnov test was used for testing of flow rate data for Normal distribution

- Analyses methods

- Since the data was no-normal, non-parametric test Kruskal-Wallis test (non-parametric ANOVA) was used to analyse the flow rates in the between the three groups with sealer type as the factor.

\section{RESULTS}

The present study is cross sectional study conducted between period of September 2016 to December 2018 in association with Dr. Bhalekar's Pathology Laboratory, Navi Mumbai.

The study includes 150 patients with age range from 24 to 51 years. All semen parameters mentioned in table 3 are studied. Patients were divided in three main age groups as, $20-30$ years, $30-40$ years and $40-60$ years. The maximum number of cases were in the age range $30-40$ years accounting for $63.3 \%(n=95 / 150)$ of the cases. $30 \%$ $(n=45 / 150)$ cases and $6.7 \%(n=10 / 150)$ cases were seen in the 20-30 years and 40-60 years age groups respectively.

According to the latest WHO recommendations, $1.5 \mathrm{ml}$ or more was taken as normal semen volume. Out of the 150 subjects in the current study $16.7 \%(n=25 / 150)$ had an ejaculate volume less than $1.5 \mathrm{ml} .83 .3 \%(\mathrm{n}=125 / 150)$ had an ejaculate volume of $1.5 \mathrm{ml}$ and above.

It is well known that sperm concentration is one of the important predictor of fertility potential. The sperm counts in the present study ranged from 0-280 million per $\mathrm{ml}$. Out of this $12 \%(\mathrm{n}=18 / 150)$ of the cases had a sperm concentration of less than 15 million $/ \mathrm{ml}$ and a total of $82 \%(n=123 / 150)$ of the analysed population was in the normal range. Azoospermia, that is no sperms in the ejaculate, was seen in $6 \%(n=09 / 150)$ individuals. Oligozoospermia were cases with counts less than 15 million/ml, normozoospermia were those with sperm counts above 15 million/ml while azoospermia had no sperms (Figure 1).

It is observed that $20.7 \%(31 / 150)$ cases alone constitutes low sperm count category. Also 6.0\% (09/150) cases fell in category of sperm count between $15-20$ million $/ \mathrm{ml}$ which forms borderline category. Fertility potential in these cases is equivocal and are to be investigated as per oligozoospermic cases.

Sperm motility being an important parameter and determinant of male fertility it should be analysed as early as possible and must be measured within 60 minutes of collection. According to the latest WHO criteria a total sperm motility of $40 \%$ with progressive movement of $>32 \%$ is taken as cut off value. ${ }^{2}$

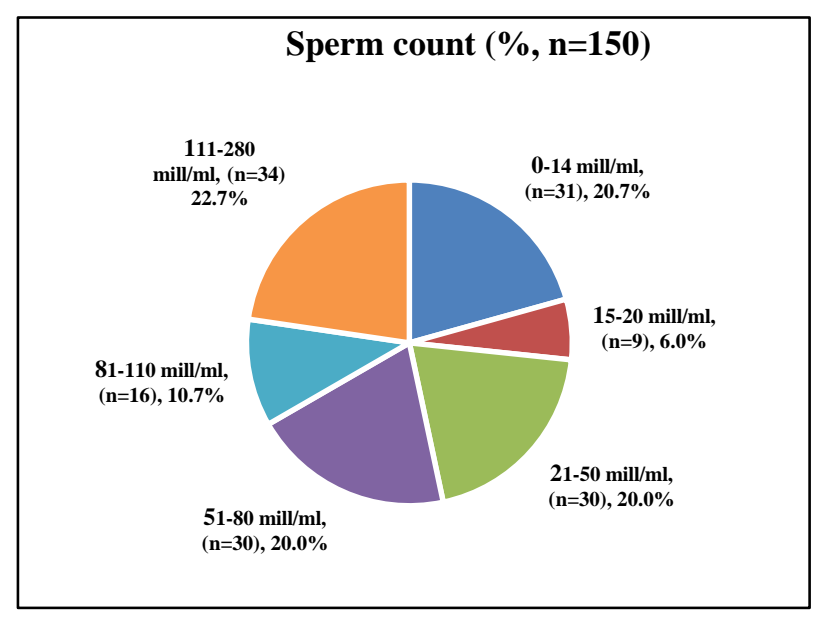

Figure 1: Distribution of cases in different sperm count groups.

Individuals above this are taken to be normal. In the present study, 80.7\% $(n=121 / 150)$ of the cases were above the reference motility and all these cases had $>32 \%$ of sperms with progressive movement. $19.3 \%(n=29 / 150)$ of the cases showed non-progressive motility. These cases were also distributed based on age group (Table 1).

Table 1: Sperm motility in different age groups and sperm count groups.

\begin{tabular}{|llll|}
\hline Age group & N & Progressive & $\begin{array}{l}\text { Non- } \\
\text { progressive }\end{array}$ \\
\hline 20-30 years. & 45 & $36(80.0 \%)$ & $09(20.0 \%)$ \\
\hline 30-40 years. & 95 & $79(83.2 \%)$ & $16(16.8 \%)$ \\
\hline $40-60$ years. & 10 & $06(60.0 \%)$ & $04(40 \%)$ \\
\hline Sperm count & & & \\
\hline $0-14 \mathrm{mill} / \mathrm{ml}$ & 31 & $9(7.4 \%)$ & $22(75.9 \%)$ \\
\hline $15-20 \mathrm{mill} / \mathrm{ml}$ & 9 & $7(5.8 \%)$ & $2(6.9 \%)$ \\
\hline $21-50 \mathrm{mill} / \mathrm{ml}$ & 30 & $25(20.7 \%)$ & $5(17.2 \%)$ \\
\hline $51-80 \mathrm{mill} / \mathrm{ml}$ & 30 & $30(24.8 \%)$ & $0(0.0 \%)$ \\
\hline $81-110 \mathrm{mill} / \mathrm{ml}$ & 16 & $16(13.2 \%)$ & $0(0.0 \%)$ \\
\hline $111-280 \mathrm{mill} / \mathrm{ml}$ & 34 & $34(28.1 \%)$ & $0(0.0 \%)$ \\
\hline Total & $\mathbf{1 5 0}$ & $\mathbf{1 2 1}(\mathbf{8 0 . 7 \%})$ & $\mathbf{2 9 ( 1 9 . 3 \% )}$ \\
\hline
\end{tabular}

The morphology was assessed on fixed stained smears of the semen samples. In the current study $6 \%$ cases had no sperms in the ejaculate (azoospermia).

One individual had a count of 5 million/ml and a borderline case of 6 million/ml sperm count with $99 \%$ abnormal morphology. In the study, five cases with count less than 5 million/ml had abnormal morphology of sperms ranging from $40-80 \%$. 
Any defects of head, neck and tail were considered as abnormal morphology. Maximum morphological defects were identified as head defects which was common finding in all age groups (Table 2) and (Figure 3).

Table 2: Sperm defects in different age groups.

\begin{tabular}{|c|c|c|c|c|c|c|c|c|c|}
\hline & \multicolumn{9}{|c|}{ Age Group } \\
\hline & \multicolumn{3}{|c|}{$20-30$ years. $(n=45)$} & \multicolumn{3}{|c|}{$30-40$ years. $(n=95)$} & \multicolumn{3}{|c|}{$40-60$ years. $(n=10)$} \\
\hline & Mean & Median & SD & Mean & Median & SD & Mean & Median & SD \\
\hline Head defects (\%) & 42 & 35 & 30 & 54 & 47 & 34 & 35 & 24 & 24 \\
\hline Neck defects (\%) & 12 & 05 & 22 & 12 & 4 & 20 & 14 & 1 & 31 \\
\hline Tail defects (\%) & 08 & 03 & 08 & 10 & 08 & 07 & 11 & 3 & 18 \\
\hline
\end{tabular}

Morphologically abnormal spermatozoa often have multiple defects (of the head, midpiece or principal piece, or combinations of these defects). A detailed study of the incidence of morphological abnormalities may be more useful than a simple evaluation of the percentage of morphologically normal and abnormal spermatozoa. Recording the morphologically normal spermatozoa, as well as those with abnormalities of the head, midpiece and principal piece, in a multiple-entry system gives the mean number of abnormalities per spermatozoon assessed. These indices have been correlated with fertility in vivo (TZI) and in vitro (SDI), and may be useful in assessments of certain exposures or pathological conditions. $^{2}$

Two indices were calculated from records of the detailed abnormalities of the head, midpiece and principal piece in a multiple-entry system. ${ }^{2}$

- The teratozoospermia index (TZI)

- $\quad$ The sperm deformity index (SDI)

\section{Calculation of these indices. ${ }^{2}$}

Each abnormal spermatozoon is scored for defects of the head, midpiece and principal piece, and for the presence of excess residual cytoplasm (volume more than one third of the sperm head size). In Teratozoospermia Index (TZI), a maximum of four defects per abnormal spermatozoon is counted: one each for head, midpiece, and principal piece and one for excess residual cytoplasm.

The Sperm Deformity Index is the number of defects divided by the total number of spermatozoa (not only the abnormal spermatozoa). It incorporates several categories of head anomaly but only one for each midpiece and principal piece defect.

WHO lower reference limit for TZI and SDI of $>4 \%$ was considered as normal, $\geq 3$ to $\leq 4 \%$ was considered as equivocal and values $<3$ was counted as abnormal. In present study, TZI* was normal in $43.3 \%(n=65 / 100)$ cases and SDI was normal in $26 \%(n=39 / 150)$ cases.
TZI* was abnormal in $23.3 \%(\mathrm{n}=35 / 100)$ cases with mean value of 1.1 and SDI was abnormal in $74 \%$ $(n=111 / 150)$ cases with mean value of 0.5 (Figure 2$)$.

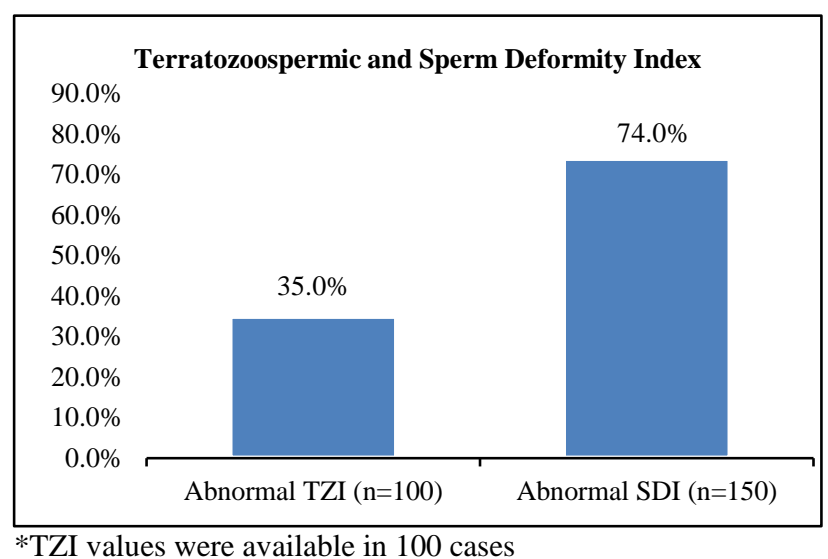

Figure 2: Percentage of cases with abnormal TZI and SDI.

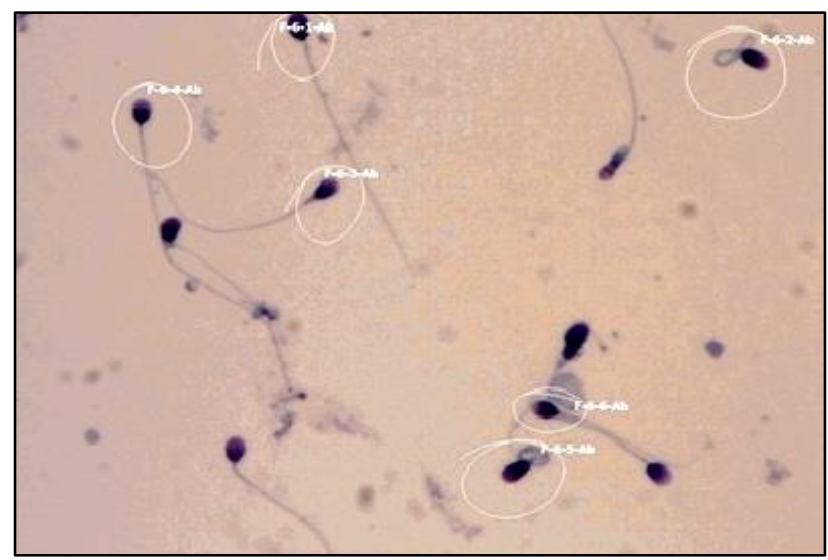

Abnormal : F-6-3-Ab HD,HD,MD| F-6-4-Ab HD| F-6-5-Ab TD| F-6-6-Ab HD,TD| F-6-1-Ab HD,MD| F-6-2-Ab TD, F- Figure, HD- Head defects, TD- Tail defects, Ab-Abnormal

Figure 3: Vitality test using eosin-nigrosin method.

In present study, fructose was present in all cases, pus cells were present in $29.5 \%$ cases, semen volume was 
low (hypospermia) in $16.7 \%$ cases and liquefaction time was normal in all cases. Cases in which pus cells were found were subjected for culture. If culture was positive, patients were cleared of infection and semen analysis was repeated. Vitality of sperms was assessed by two methods: Eosin Nigrosin method (Figure 3) and Hypoosmotic swelling (HOS) test.

Vitality test using hypo-osmotic swelling is an alternative to dye exclusion. Spermatozoa with intact membranes swell within 5 minutes in hypo-osmotic medium and all flagellar shapes are stabilized by 30 minutes. $^{2}$

In present study, $17.3 \%(\mathrm{n}=26)$ cases showed abnormal hypo-osmotic swelling test. This is useful when staining of spermatozoa must be avoided, e.g. when choosing spermatozoa for ICSI. $^{2}$ An age specific comparative analysis of the mean sperm counts, total motility and normal morphology revealed a decline in the average values of these parameters with age (Table 3 ).

Table 3: Semen parameters in different age groups.

\begin{tabular}{|c|c|c|c|c|}
\hline & 20-30 years $(n=45)$ & $30-40$ years $(n=95)$ & $40-60$ years $(n=10)$ & Total $(n=150)$ \\
\hline & Mean (SD) & Mean (SD) & Mean (SD) & Mean (SD) \\
\hline Age (years.) & $28.00(1.75)$ & $34.42(2.97)$ & $44.10(2.77)$ & $33.14(4.90)$ \\
\hline Semen volume $(\mathrm{ml})$ & $2.93(1.87)$ & $2.75(1.43)$ & $2.00(0.97)$ & $31.37(8.45)$ \\
\hline Liquefaction time (min) & $32.00(13.71)$ & $30.58(4.24)$ & $36.00(6.58)$ & $75.85(71.58)$ \\
\hline Sperm count $(\mathrm{mill} / \mathrm{ml})$ & $88.64(82.86)$ & $71.42(66.04)$ & $60.30(66.54)$ & $73.01(14.00)$ \\
\hline Viable sperms (\%) & $76.13(11.67)$ & $71.84(14.25)$ & $70.57(21.28)$ & $70.18(11.72)$ \\
\hline HOS reactive $(\%)$ & $72.83(10.76)$ & $69.23(11.70)$ & $67.43(16.11)$ & $22.55(20.29)$ \\
\hline Rapid progressive (\%) & $22.50(16.54)$ & $22.46(21.23)$ & $24.00(29.33)$ & $34.02(14.33)$ \\
\hline Slow progressive (\%) & $34.60(13.03)$ & $33.67(14.38)$ & $35.29(21.87)$ & $13.65(8.55)$ \\
\hline Non-progressive (\%) & $14.88(10.02)$ & $13.22(7.49)$ & $12.14(12.65)$ & $29.76(14.34)$ \\
\hline Immotile $(\%)$ & $28.03(11.60)$ & $30.62(15.51)$ & $28.57(13.45)$ & $45.53(27.99)$ \\
\hline Normal morphology $(\%)$ & $50.90(28.06)$ & $42.35(27.39)$ & $56.14(32.23)$ & $53.86(28.33)$ \\
\hline Abnormal morphology (\%) & $46.98(28.79)$ & $57.65(27.39)$ & $43.86(32.23)$ & $56.43(29.54)$ \\
\hline Defective morphology $(\%)$ & $48.88(29.33)$ & $60.58(28.68)$ & $45.57(34.93)$ & $49.59(33.05)$ \\
\hline Head defects $(\%)$ & $42.05(29.57)$ & $54.04(34.37)$ & $34.86(24.45)$ & $12.42(20.75)$ \\
\hline Neck defects $(\%)$ & $12.35(21.64)$ & $12.35(19.69)$ & $13.71(31.07)$ & $9.11(8.00)$ \\
\hline Tail defects $(\%)$ & $7.58(7.89)$ & $9.64(6.78)$ & $11.00(18.47)$ & $56.57(19.20)$ \\
\hline Sperm deformity index & $0.62(0.51)$ & $0.78(0.54)$ & $0.60(0.57)$ & $0.72(0.54)$ \\
\hline Teratozoospermic index & $1.35(1.12)$ & $1.22(0.37)$ & $1.20(0.32)$ & $1.25(0.68)$ \\
\hline
\end{tabular}

\section{DISCUSSION}

Childbearing is considered as an essential part of living and yardstick by which women's worth is measured especially in a developing country. So it invites social stigma. It's no longer a private sorrow instead it's coming out of the woodwork due to its social and interpersonal ramifications. Besides, recent researches have proved that problem is not gender specific. Semen analysis remains the cornerstone to investigate male infertility.

\footnotetext{
"Male factor" infertility (MFI) is considered as a change in sperm concentration and/or motility and/or morphology in at least one sample of two sperm analyzes, collected 1 and 4 weeks apart. ${ }^{12}$ Most recent WHO (2010) manual for semen analysis have changed nomenclature from "normal" to "reference values" with respect to sperm concentration, motility, morphology and all other semen parameters. Males with sperm parameters
}

below the WHO normal values or reference values are considered to have male factor infertility. ${ }^{13}$

The study was a cross-sectional study with a population of 150 individuals. Maximum number of cases were in the age range 30 - 40years. A relatively higher mean age of 36.8years and 34 years has been reported by other authors. $^{14,15}$ However, a mean age of 30 years in concordance with our finding was observed by Jajoo $\mathrm{S}$ et al. ${ }^{16}$ Male fertility usually peaks at around 35 years of age and declines after 45 years of age. ${ }^{17}$ The changes associated with aging are moderate, but significant, although the capacity to fertilize is maintained. ${ }^{18}$

According to the latest $\mathrm{WHO}$ recommendations, the lower reference value for semen volume is $1.5 \mathrm{ml}^{2}$ with reference to this $16.7 \%$ of our study population had low volume while the remaining $83.3 \%$ was within the normal range. Precise measurement of volume is essential in any semen analysis as it allows the total count of 
spermatozoa and non sperm cells in the ejaculate to be assessed.

Volume is generally assessed in a graduated glass cylinder with a flared top. Ineffective collection may adversely affect volume assessment. In addition, a variable relationship exists between the frequency of emissions, continence and seminal volume. ${ }^{19,20}$ Ejaculated seminal volume is a parameter that reflects abnormalities in accessory sex glands fluid synthesis i.e. seminal vesicle which forms a bulk. Low semen volume is characteristic of obstruction of the ejaculatory duct or congenital absence of the vas deferens. ${ }^{2}$ High semen volume may on the other hand reflect exudation in cases of active inflammation of accessory organs. ${ }^{2}$

Sperm concentration is often proposed to be predictors of fertility potential. In recent years there have been reports of declining sperm concentration in men around the world. $^{21,22}$ The new WHO 2010 guidelines has taken lower reference limit of 15 million/ml with values above these taken as normal. ${ }^{2}$ Oligozoospermia (sperm counts $<15$ million/ml) in the present study was seen in $12 \%$ of the cases while higher rates of $23.2 \%, 32 \%$ and $25.6 \%$ are reported. ${ }^{23-25}$ Although lower values of $11.11 \%$ have also been observed. ${ }^{10}$

It has been suggested by authors that low sperm counts are among the most common cause of male infertility. ${ }^{23}$ Association of oligozoospermic semens with increased morphological abnormalities has been suggested by Butt et al. ${ }^{10}$

Azoospermia, defined as absence of spermatozoa in the ejaculation was seen in $6 \%$ of the cases which was lower compared to those seen in other studies such as $14.8 \%$, $12.3 \%, 28.6 \% .^{10,26,27}$ The problem of azoospermia is thought to be associated with sperm production or sperm transport. ${ }^{10}$

$82 \%$ of the analyzed subjects had normal sperm counts, which was higher than reported by Butt et al. ${ }^{10}$ However these values are much higher than other reports such as $20 \%, 36.7 \%$ and $51.8 \% .^{26-28}$ More so, it may be noted that normal semen counts are a common event in infertile males, where the cause may be other factors such as immune related and marked biological variation. ${ }^{29}$

Assessment of sperm motility is essential as the spermatozoa have to travel in the female genital tract to fertilize the oocyte, a requisite of normal pregnancy. ${ }^{10}$ It is a critical parameter which indicates semen quality and fertility potential. As per the WHO 2010 recommendations, samples having $40 \%$ motile sperms with $32 \%$ showing progressive, motility are considered normal. ${ }^{2}$ In the present study $121(80.7 \%)$ cases were above the reference motility and all these cases had $>32 \%$ of sperms with progressive movement. This was in concordance with $76 \%$ as reported by Okon E et al, and higher as compared to value of $62.02 \%$ reported by Alemnji. ${ }^{26,14}$

Sperm morphology along with motility and sperm count is also an important contributing factor in male fertility. The total number of morphologically normal spermatozoa in the ejaculate is of biological significance, the lower reference limit for normal sperm morphology is $4 \%$ as per the latest WHO guidelines. ${ }^{2}$ The WHO criteria for morphology has seen a marked change over the years from $50 \%$ and above to as low as $4 \%$ in the 5 th edition. ${ }^{30}$ Sperm morphology is assessed by microscopic examination. Normal sperm contains head, middle piece, and tail. Morphological changes (teratozoospermia) were defects in the head, neck, midpiece and tail of spermatozoa. The details of the type of defects were recorded in present study. Some studies show that these defects have a prognostic bearing as some defects are irreversible, and others which are due to acquired/environmental factors can be reversible. ${ }^{31,32}$ Most of the studies describe the association of low sperm count and abnormal morphology. They studied that sperm morphological defects increases with decreasing sperm count. ${ }^{33}$ Only few studied the defects with normal sperm counts also. ${ }^{34}$ Defects in the head are the most common defects. $^{35}$

Clinical significance of some of these defects described by many authors such as tapering and megaloheads are reversible defects. It is mainly due to ongoing stress or some medication. After stopping the precipitating factor, most of them revert back. These defects increase with decreasing sperm count. ${ }^{33}$ Amorphous head is a defect with genetic aberration, so this is a severe form and incapable of fertilization. Globozoospermia small round head with no acrosome are also genetically determined and due to the absence of acrosin unable to bind to zona pellucida. Small head spermatozoa also have very small, abnormally formed acrosome. Large head spermatozoa have severely abnormal megaloheads. ${ }^{32}$ Teratozoospermia has a deleterious effect on the rate of fertilization. ${ }^{36}$

Most common morphological defects were observed in head of sperms which is in concordance with Goyal et al. ${ }^{37}$ Present study was limited by availability of proper environmental factors and other relevant history and follow up. Some have noted the association of multiple defects with increased chances of spontaneous abortions. ${ }^{38}$ In present study, many cases with multiple combined abnormalities was also found. However, the study is limited owing to lack of follow-up.

Semen is normally ejaculated as a liquid, immediately gels, and liquefies within five to 20 minutes. Less than one percent of specimens will fail to liquefy. Such an event makes the analysis difficult, but is not clearly related to infertility. Viscosity is assessed by pouring the specimen from the collection bottle into a graduated cylinder, and grading on a scale of zero (normal) to four 
is done. A normal sample is capable of being poured in single, small droplets; grade 4 specimen remains as a solid blob. As with non - liquefaction, high viscosity makes analysis extremely difficult but does not interfere with fertility. ${ }^{39}$ In present study, liquefaction time was in normal range in all cases.

The $\mathrm{pH}$ of fresh semen will be 7.3-7.7. This will shift to the more alkaline range when the sample is left standing. With further passage of time the accumulation of lactic acid will make the sample more acidic. In present study, $\mathrm{pH}$ was in normal range only in 3 cases. Fructose is produced by the seminal vesicles. It will be absent from the semen in three clearly defined circumstances: in a rare form of retrograde ejaculation, when both ejaculatory ducts are obstructed and in azoospermic men with congenital bilateral absence of the vas deferens. ${ }^{40}$ In present study, fructose was present in all cases.

Reproductive quiescence in women is seen between 45 55 years of age. This is not the case with men, who age gradually. Still, they commonly do not experience complete reproductive senescence and maintain spermatogenesis well into old age. ${ }^{13}$ However, increasing age significantly influences semen parameters required for healthy male fertility. ${ }^{13}$ Age related changes on the seminal parameters were also evaluated in present study, it was noted that mean sperm counts, total motility and normal morphology revealed a decline in the average values of these parameters with age, this was in concordance to similar studies conducted in past. ${ }^{13}$

\section{CONCLUSION}

Although semen analysis is first and most informative investigation for the evaluation of male factor infertility, studying individual semen parameters and sperm function and increasing its awareness in general population especially in developing countries is equally important. Besides, it is necessary to acknowledge its limitation with respect to collection, processing, evaluation and biological variation of samples. Also, a normal semen analysis may not prove successful fertility potential of an individual. Poor sperm function is usually associated with high proportion of abnormal spermatozoa. Besides morphologically normal-appearing spermatozoa should also be further investigated for normal sperm function and DNA content as morphological normal sperms does not necessarily imply normal sperm function. In addition, male fertility and various semen parameters are seen to decline with age in this part of India.

\section{ACKNOWLEDGMENTS}

Authors would like to thank Mrs. Rupali Suryawanshi (BSc. DMLT) and Mrs. Akshata Rikame (HSC CMLT), Laboratory Technician for their support during study.

Funding: No funding sources Conflict of interest: None declared

\section{Ethical approval: Not required}

\section{REFERENCES}

1. Thonneau P, Marchand S, Tallec A, Ferial ML, Ducot B, Lansac J, et al. Incidence and main causes of infertility in a resident population $(1,850,000)$ of three French regions (1988-1989). Hum Reprod. 1991;6:811-6.

2. World Health Organization. Semen analysis. In: WHO laboratory manual for the Examination and processing of human semen. 5th ed. Geneva: World Health Organization. 2010:10-168.

3. Agarwal A, Sekhon LH. The role of antioxidant therapy in the treatment of male infertility. Hum Fertil. 2010;13:217-25.

4. Carlsen E, Giwercman A, Keiding N, Skakkebaek NE. Evidence for decreasing quality of semen during past 50 years. British Med J. 1992;305:609-13.

5. Auger J, Kunstmann JM, Czyglik F, Jouannet P. Decline in semen quality among fertile men in Paris during the past 20 years. $\mathrm{N}$ Engl $\mathrm{J}$ Med. 1995;332:281-5.

6. Lackner J, Schatzl G, Waldhör T, Resch K, Kratzik C, Marberger M. Constant decline in sperm concentration in infertile males in an urban population: Experience over 18 years. Fertil Steril. 2005;84:1657-61.

7. Marimuthu P, Kapilashrami MC, Misro MM, Singh G. Evaluation of trend in semen analysis for 11 years in subjects attending a fertility clinic in India. Asian J Androl. 2003;5:221-5.

8. Fisch H, Goluboff ET, Olson JH, Feldshuh J, Broder SJ, Barad DH. Semen analyses in 1,283 men from the United States over a 25-year period: No decline in quality. Fertil Steril. 1996;65:1009-14.

9. Giwercman A, Skakkebaek NE. The human testis An organ at risk? Int J Androl. 1992;15:373-5.

10. Butt F, Akram N. Semen analysis parameters: Experiences and insight into male infertility at a tertiary care hospital in Punjab. J Pak Med Assoc. 2013;63(5):558-62.

11. Fisch H. Declining worldwide sperm counts: disproving a myth. Urol Clin North Am. 2008;35:137-46.

12. World Health Organization. WHO Laboratory Manual for the Examination of Human Semen and Semen-Cervical Mucus Interaction. 4th ed. Cambridge: Cambridge University Press. 1999:1-86.

13. Plachot M, Allart BJ, Mayenga JM, Chouraqui A, Tesquier L, Serkine AM. Outcome of conventional IVF and ICSI on sibling oocytes in mild male factor infertility. Hum Reprod. 2002;17:362-9.

14. Alemnji GA, Thomas KD, Oyelese AO, Ojedije TO. The semen of fertile black males: analysis of 100 consecutive cases. Ann Saudi Medicine. 2002;22:947.

15. Lampiao F, Kutengule A. Characteristics of semen parameters of Malawian men from couples seeking 
assisted reproduction. World J Obstet Gynecol. 2013;2:181-4.

16. Jajoo S, Kalyani KR. Prevalence off abnormal semen analysis in patients of infertility at a rural setup in Central India. Int J Reprod Contracept Obstet Gynecol. 2013;2:161-4.

17. Samal S, Dhadwe K, Gupta U, Gupta NK. Epidemiological study of male infertility. Ind Med Gazette. 2012;5:174-80.

18. Gallardo E, Simon C, Levy M, Guanes PP, Remohi J, Pellicer A. Effect of age on sperm fertility potential: oocyte donation as a model. Fer Steril. 1996;66:260-4.

19. Freund M. Inter-relationships among the characteristics of human semen and factors affecting semen-specimen quality. J Reprod Fertil. 1962;4:4359.

20. Freund M. Effects of frequency of emission on semen output and an estimate of daily sperm production in man. J Reprod Fertil. 1963;6:269-85.

21. Lampiao F, Kutengule A. Characteristics of semen parameters of Malawian men from couples seeking assisted reproduction. World J Obstet Gynecol. 2013;2:181-4.

22. Kumar N, Singh AK, Choudhari AR. Impact of age on semen parameters in male partners of infertile couples in a rural tertiary care center of central India: A cross-sectional study. Int $\mathrm{J}$ Reprod Bio Med. 2017;15(8):497-502.

23. Khan MS, Deepa F, Ahmed Z, Tahir F, Khan MA. Assessment of male reproductive health by conventional method of semen analysis. J Ayub Med Coll Abbottabad. 2011;23:84-8.

24. Shaikh AB, Khalique K, Tariq G, Soomro N. Pattern of semen abnormalities in couples with male factor infertility. Pak J Surg. 2011;27:204-8.

25. Owolabi AT, Fasubaa OB, Ogunniyi SO. Semen quality of male partners of infertile couples in Ile-Ife, Nigeria. Niger J Clin Pract. 2013;16:37-40.

26. Okon BO, Fasubaa OB, Togun RA, Fakunle JB, Aderemi A, Adediran T. Semen profile in Ile-Ife, Nigeria in relation to New Who Guidelines. J Med Sci. 2011;2:879-84.

27. Wazir BG, Orakzai AN, Ikramullah, Ahmad N, Rafiq M. Male factor infertility: five years experience. Ann Pak Inst Med Sci. 2010;6:7-10.

28. Opoku A, Boateng D, Quansah DY, Addo BK, Krokoe AF. Semen characteristics of male infertile couples in the kumasi metropolis: a study of primary and secondary infertile couples. $\mathrm{Br} \mathrm{J}$ Med Res. 2014;4(6):1432-41.

29. Hamada A, Esteves SC, Nizza M, Agarwal A. Unexplained male infertility: diagnosis and management. Int Braz J Urol. 2012;38:576-94.
30. Padiyan N. Semen analysis- a numbers game, chettinad. Health City Med J. 2012;1:2-3.

31. Singh S, Sharma S, Jain M, Chauhan R. Importance of papanicolaou staining for sperm morphologic analysis: comparison with an automated sperm quality analyzer. Am J Clin Pathol. 2011;136:247-51

32. Menkveld R. Clinical significance of the low normal sperm morphology value as proposed in the fifth edition of the WHO laboratory manual for the examination and processing of human semen. Asian J Androl. 2010;12:47-58.

33. Karabulut A, Tekin A. Alterations in the morphology and motility of spermatozoa: relation with total sperm count. Pam Med J. 2013;6:1-4.

34. Rocha FT. Sperm parameters in men with suspected infertility. Sperm characteristics, strict criteria sperm morphology analysis and hypoosmotic swelling test. J Reprod Med. 2001;46:577-82.

35. Nikolettos N, Küpker W, Demirel C, Schöpper B, Blasig C, Sturm R, et al. Fertilization potential of spermatozoa with abnormal morphology. Hum Reprod. 1999;14(1):47-70.

36. Mendoza JC, Cubillos J, Ortiz G, Arango A, Diaz M, Ruiz H. Is reliable the new semen analysis of the WHO laboratory manual for the diagnosis of the male factor in an infertile population? JBRA Assist Reprod. 2013;17(2):98-100.

37. Goyal R, Kotru M, Gogia A, Sharma S. Qualitative defects with normal sperm counts in a patient attending infertility clinic. Indian J Pathol Microbiol. 2018;61:233-5.

38. Cao X, Cui Y, Zhang X, Lou J, Zhou J, Wei R, et al. The correlation of sperm morphology with unexplained recurrent spontaneous abortion: A systematic review and meta-analysis. Oncotarget. 2017;8:55646-56.

39. Amelar RD, Dubin L. Semen analysis, in Amelar RD, Dubin L, Walsh PC (eds): Male infertility. Philadelphia, W.B. Saunders Co., 1977:105-140.

40. Keiserman WM, Dubin L, Amelar RD. A new type of retrograde ejaculation: Report of three cases. Fertil Steril. 1974;25:1071-2.

Cite this article as: Bhalekar S, Ganorkar S, Bhalekar H, Roplekar P. Semen analysis and sperm function parameters in patients with infertility in Navi Mumbai and Panvel region. Int J Reprod Contracept Obstet Gynecol 2019;8:4169-76. 